\title{
The effect of the bio-fertilizer Seek in The content of leaves and roots of nutrientsN,p,K for seedlings of two fig cultivars Ficus carica $L$
}

\author{
${ }^{1}$ Aola w. Taher, ${ }^{2}$ Ihsan J.Ethbeab \\ ${ }^{12}$ Dhi Qar University - College of Agriculture and the Marshes - Department of Horticulture and Landscape \\ ${ }^{1}$ Email:aolawasfi93@gmail.com \\ 2Email:ihsanjali198415@gmail.com
}

\begin{abstract}
:
This experiment was conducted in the wooden canopy of the Department of Horticulture and Landscaping - College of Agriculture and the Marshes -University of Dhi Qar in the winter season 2020-2021 to study the bio-fertilizer with four concentrations $(0,500,1000,1500) \mathrm{g}$. seedlings and two varieties of fig plant (Black Diyala, Waziri) and the interaction between them. The results showed the superiority of the cultivar Waziri in the traits (the content of the roots of phosphorous and the content of the roots of potassium), which reached $(0.4233 \%, 1.1983 \%$ The concentration exceeded $1500 \mathrm{~g}$. Shell-1 of the bio-fertilizer in the characteristics of (leaved content of phosphorous, content of leaves of potassium, content of roots of nitrogen, content of roots of phosphorus, content of roots of potassium) reached $(0.545 \%$ , $1.545 \%, 1.6867 \%, 1.5683 \%$, reached $1.4017 \%$ ) compared to the comparison treatment and the concentration exceeded $1000 \mathrm{gm}$. Shela-1 in the nitrogen content of leaves $2.002 \%$ The results of the statistical analysis indicate the presence of significant interactions that differ according to the variety and the concentration of the bio-fertilizer.
\end{abstract}

Keywords: bio-fertilizer, figs, Seek, Ethbeab ,Wasfi

\section{INTRODUCTION}

figs (Ficus carica L.) is a deciduous fruit belonging to the genus Ficus, which belongs to the family Moraceae. This genus includes 400 species and 700 cultivars. It is believed that its original home is the Arabian Peninsula, and Muslims spread its cultivation in North Africa and the Mediterranean countries (Ibrahim, 1996). Turkey occupies the first place for fig production in the world as well as in the cultivated area, followed by Greece and California in the United States, and the world's annual production rate of figs is 1935000 tons (Ferguson et al., 1999). Figs are grown for their fruits, which are consumed either fresh or dry, and their fruits are used in many food industries (jams, sweets,) and figs are of high nutritional value due to their content of carbohydrates and proteins, as they contain 3.60/0 protein, 52.9 0/0 total sugars, $1.30 / 0$ fats, in addition to many vitamins and minerals, as they are rich in iron, sodium, calcium, vitamins $\mathrm{A}$ and $\mathrm{C}$ (Crush and Suhar, 1999). The fig leaves contain the compound Methoxsalen, which is used to treat Vitiligo. and psoriasis and skin cancer diseases resulting from exposure to ultraviolet rays (Isaac, 2000). There is a need for some strategies that increase soil quality and maintain its fertility. One of these strategies is useNS bio fertilizer where Biofertilizer keeps the soil environment rich in nutrients grand NSNitrogen, Phosphate, and Potassium (Sinha, Valani et al. 2010) However, biological fertilizers cannot replace chemical fertilizers, but it is considered a way to reduce the use of chemical 
fertilizers. (Okure, 2018 ) There are many bio-fertilizers and their content of nutrients, micro-organisms and organic matter varies, and these fertilizers include bio-fertilizer seek (Atia, 2020). Biofertilizers stimulate physiological or natural processes that increase the absorption of nutrients; It stimulates the production of metabolic substances directly related to plant growth such asAuxins and Gibberellins, Cytokinins), as The use of bio-fertilizer increases the fixation of bio-nitrogen and plant growth hormones that improve the development of root systems and this method is very important to protect the environment from pollution ,In addition, these microorganisms stimulate root growth . Sex bacteria may workPseudomonas It also acts as a solvent for phosphates, which increases the phosphorous available to plants in the soil (Buragohain, Sarma et al. 2018) thatAvailability of good seedlings that contribute to the increase in the development and spread of any type of fruit, and the availability of these seedlings requires adequate care for these seedlings in the nurseries by conducting a lot of horticultural operations, especially in terms of fertilization, as the composting process is among the most important processes that contribute to the growth of seedlings and trees Fruit well and early in the fruiting stage, fruit seedlings deplete a quantity of nutrients necessary for the purpose of their growth, so various of these elements must be provided in the soil planted in it in a ready-made way so that the plant can absorb and benefit from it in its growth and production, through the composting process and with appropriate concentrations.Excessive use of chemical fertilizers has become a threat to the lives of citizens and infects them with serious diseases such as cancer and others, after fertilizers were one of the most important factors that helped in the increase and development of agricultural production, but the unjust and indiscriminate use of them by farmers has left negative effects on the environment and the health of the citizen, as it interacts with the soil and leaves Negative effects on the various elements of the environment, and excessive use leads to numerous environmental problemsthis ( Al Allaf, 2014 ) There are several varieties of figs that are widely cultivated in Iraq, including the Black Diyala, whose fruits are black, and Al-Waziri, whose fruits are yellow (Al-Jumaili and Al-Dujaili, 1989). . Some researchers mentioned that there is a difference in the response of fruit varieties in their response to fertilization processes, and this difference is due to genetic factors among them (Al-Safi, 1997) In his study on fig seedlings and (Al-Zebari, 2011) In his study on the varieties of figs. Biofertilizers affect many physiological processes inside the plant, including photosynthesis and respiration, as well as the absorption of nutrients And Working Fertilisers The vitality of releasing large quantities of nutrients ready for absorption by the roots of plants, and then improving the physiological processes within the plant the most important Increasing the efficiency of photosynthesis in Leaves and increase the concentration of elements in the leaves and roots( Butler, 2006) . Male (Vandenham, 1997 inhis study On the fig trees Use of bio-fertilizer EM-1led to me An increase in atmospheric nitrogen fixation, an increase in the decomposition of organic matter, and an increase in thaw Phosphorous as well as increasing the plant's ability to retain organic compounds and increasing the concentration of nutrients NPKIn the leaves and roots, as well as carbohydrates .Biofertilizers increase growth The root system of the plant, because Containing Some plant growth stimulants Which increases the readiness of nutrients Leading to me Increasing the efficiency of root absorption of nutrients in the soil (the local ,2005). It was mentioned (Al-Samarrai, 2009) that treating citrus seedlings with biofertilizer increases the availability of nutrients in the soil and thus obtaining significant differences in the content of leaves from chlorophyll, carbohydrates and mineral elements. pointed out (TheFriend ,2015 ) to me that Use of biofertilization at a rate It had a significant effect in increasing the content leaves and the roots ManalMineral elements and carbohydrates in olive trees .Mohjj and Elhayani (2015) conducted a studyaround Effect addition Azospirillumbrasilemse and Azotobacterchroococcum, as well as nitrogen-fixing bacteria on Ardabili, Muhari and Qaisi 
apricot cultivars, and found that the addition of these organisms led to a significant increase in the chlorophyll content of leaves and theCarbohydrates and major minerals. Male (El-sabbagh and others, 2011)that The use of bio-fertilization four Species she (Biogen, Nitrobeine, Rhizobacterine, dry yeast) on two grape cultivars, Thompson seedless and Flame seedless.that addition Fertilisers single vitality or nested with some of them Led to me Significant increase in nitrogen, phosphorous, and potassium inleaves. And in studying conducted From before (El-Khayat and Abdel Rehiem, 2013)that addition biofertilizers) Nitrobin and Phosphorin) individuallyor overlapping with three concentrations $(100,200,300) \mathrm{g}$. Tree-1 to ThreeSpecies from trees tangerines are (Balady, Emperor, and Clementine)Led add to me Increase content leaves of the nutrients N,P,K and carbohydratesand for all Categories .

\section{MATERIALS AND METHODS}

The experiment was conducted in the canopy of the Department of Horticulture and Landscaping at the College of Agriculture and Marshes - Dhi Qar University for the agricultural season 2020-2021.. I used the bio fertilizer (seek) produced by the Chinese company (seek bio technology) with four concentrations $(0,500,1000,1500) \mathrm{g}$. Seedlings and according to the recommendation of the producing company, and the second factor is the varieties (Black Diyala and AlWaziri) with three replications. 96 seedlings of good-growing, homogeneous, one-year-old figs, planted in plastic anvils, the size of $1 \mathrm{~kg}$, were selected from the nursery belonging to the Department of Horticulture / Najaf Branch, with 48 seedlings for each variety. After that, the seedlings were transferred to two anvils with a size of $10 \mathrm{~kg}$. Then, samples of the surrounding soil with a diameter of $30 \mathrm{~cm}$ were taken and the soil properties were estimated before conducting the treatments. The seedlings were transferred to the experimental site on 1/2/2021 with a total of 96 seedlings. All service operations of hoeing, fertilizing and pest control were carried out for the seedlings according to the recommended program by the nursery affiliated to the Ministry of Agriculture / Horticulture Department / Najaf Branch. The seedlings were divided into three sectors with 32 seedlings for each replicate, as each 4 seedlings represented one experimental unit. 3/2/2021, where the experimental transactions including all possible combinations were distributed among the experimental workers as a factorial experiment that included eight transactions with three replications according to the design of randomized complete sectors (RCBD Randomized Complete Block Design (Al-Rawi and Khalaf Allah, 2000).

\section{Studied traits}

\section{1-Nitrogen ( \% )}

Nitrogen pot in the leaves kildall device (Kjeldahl Apparatus) and as mentioned in Al-Sahaf, (1989)

\section{2-phosphorous ( \%)}

The phosphorous content of leaves was estimated using the method of ammonium molybdate and ascorbic acid, as mentioned in Al-Sahaf, (1989).

\section{3- Potassium (\%)}

The potassium content of leaves in the digested sample was estimated as mentioned in Horneck and Hanson (1998) using a Flame Photometer (ELICO, model CL 361, Indian origin) . 


\section{III.RESULTS}

\section{1- Nitrogen content of leaves $\%$}

The results presented in the table indicate 15th The biological fertilizer had a significant effect on the rate of Paper content of nitrogen, the concentration exceeded 1000 gr. -1 seedlings of bio-fertilizer were significant in giving the highest rate in a Paper content of nitrogen reach $2.002 \%$ Compared to the lowest rate of content leaves from nitrogen reach $1.655 \%$ When the comparison treatment is $0 \mathrm{~g}$. seedling -1 . The results presented in the same table indicate that the variety did not have a significant effect on the rate of Paper content of nitrogen

The results of the same table show the presence of significant interactions, as the reason for the interference consists of 1500 g. -1 seedlings of bio-fertilizer with cultivar Waziri the highest ratein a Paper content of nitrogen $1.960 \%$ Whereas, the interference formed was 0 g. -1 seedlings of bio-fertilizer with cultivarmy minister lowest rate Paper content of nitrogen reached $1.653 \%$.

Table (1): the effect ofimpregnated bio ( seek ) and the variety and the interaction between them in the nitrogen content of leaves $\%$.

\begin{tabular}{|c|c|c|c|c|c|}
\hline \multirow{2}{*}{$\begin{array}{c}\text { Varieties Effect } \\
\text { Rate }\end{array}$} & \multicolumn{6}{|c|}{ concentrationimpregnated Bio (gm. seedlings -1) } & \multirow{2}{*}{ Categories } \\
\cline { 2 - 5 } & 1500 & 1000 & 500 & 0 & black Diyala \\
\hline 1.893 & 1.953 & 1.993 & 1.970 & 1.657 & Al-Waziri \\
\hline 1.895 & 1.960 & 2.010 & 1.957 & 1.653 & $\begin{array}{c}\text {. effect } \\
\text { rateimpregna } \\
\text { ted bio }\end{array}$ \\
\hline & 1.957 & 2.002 & 1.963 & 1.655 & $\begin{array}{c}\text { The slightest } \\
\text { difference } \\
\text { LSD (0.05) }\end{array}$ \\
\hline
\end{tabular}

\section{1- The phosphorous content of the leaves \%}

The results presented in the table indicate 16 The biological fertilizer had a significant effect on the rate of Paper content of phosphorous, the concentration exceeded 1500 gr. -1 seedlings of bio-fertilizer were significant in giving the highest rate in a Paper content of phosphorous reached $0.545 \%$ Compared to the lowest rate of content leaves from phosphorous reach $0.353 \%$ When the comparison treatment is $0 \mathrm{~g}$. seedling -1 . The results presented in the same table indicate that the variety did not have a significant effect on the rate of Paper content of phosphorous. The results of the same table show the presence of significant interactions, as the reason for the interference consists of 1500 g. - 1 seedlings of bio-fertilizer with cultivarblack Diyala highest rate in a The content of papers fromphosphorous reached $0.563 \%$ Whereas, the interference formed was $0 \mathrm{~g}$. -1 seedlings of bio-fertilizer with cultivarblack Diyala lowest rate NSPaper content of phosphorous reached $0.340 \%$. 
Table (2): the effect ofimpregnated bio ( seek ) and class and overlap them in contentLeaves of phosphorous

\begin{tabular}{|c|c|c|c|c|c|}
\hline \multirow{2}{*}{$\begin{array}{c}\text { Varieties Effect } \\
\text { Rate }\end{array}$} & \multicolumn{4}{|c|}{. concentrationimpregnated Vital (mine. seedlings-1) } & \multirow{2}{*}{ Categories } \\
\hline & 1500 & 1000 & 500 & 0 & \\
\hline 0.480 & 0.563 & 0.517 & 0.500 & 0.340 & black Diyala \\
\hline \multirow[t]{2}{*}{0.433} & 0.527 & 0.370 & 0.470 & 0.367 & Al-Waziri \\
\hline & 0.545 & 0.443 & 0.485 & 0.353 & . effect rateimpregnated bio \\
\hline \multicolumn{5}{|c|}{ Theimpregnated bio $=0.0907$ class $=0.0641$} & $\begin{array}{l}\text { The slightest difference } \\
\text { LSD (0.05) }\end{array}$ \\
\hline
\end{tabular}

\section{2- Content Leaves of potassium\%}

The results presented in the table indicate 17 The biological fertilizer had a significant effect on the rate of Paper content of phosphorous, the concentration exceeded 1500 gr. -1 seedlings of bio-fertilizer were significant in giving the highest rate NSPaper content of potassium reached $1.545 \%$ Compared to the lowest rate of content leaves from potassium reach $1.033 \%$ When the comparison treatment is $0 \mathrm{~g}$. seedling -1 . The results presented in the same table indicate that the variety did not have a significant effect on the rate of Paper content of potassium . The results of the same table show the presence of significant interactions, as the reason for the interference consists of 1500 g. - 1 seedlings of bio-fertilizer with cultivarblack Diyala highest rate NSPaper content of Potassium reached1.600 $\%$ Whereas, the interference formed was 0 g. -1 seedlings of bio-fertilizer with cultivarblack Diyala lowest rate NSPaper content of potassiumreached $0.977 \%$.

Table (3): the effect ofimpregnated bio ( seek ) and the cultivar and the interaction between them in the potassium content of leaves $\%$

\begin{tabular}{|c|c|c|c|c|c|}
\hline \multirow{2}{*}{$\begin{array}{c}\text { Varieties Effect } \\
\text { Rate }\end{array}$} & \multicolumn{4}{|c|}{. concentrationimpregnated Bio (gm. seedlings $\mathbf{- 1}$ ) } & \multirow{2}{*}{ Categories } \\
\hline & 1500 & 1000 & 500 & 0 & \\
\hline 1.346 & 1.600 & 1.530 & 1.277 & 0.977 & black Diyala \\
\hline \multirow[t]{2}{*}{1.357} & 1.490 & 1.417 & 1.433 & 1.090 & Al-Waziri \\
\hline & 1.545 & 1.473 & 1.355 & 1.033 & $\begin{array}{l}\text {. effect } \\
\text { rateimpregna } \\
\text { ted bio }\end{array}$ \\
\hline \multicolumn{5}{|c|}{$\begin{aligned} \text { Theimpregnated bio } & =0.1175 \text { class }=0.0831 \\
\text { overlap } & =0.1662\end{aligned}$} & $\begin{array}{l}\text { The slightest } \\
\text { difference } \\
\text { LSD (0.05) }\end{array}$ \\
\hline
\end{tabular}




\section{3- The nitrogen content of the roots $\%$}

The results presented in the table indicate 18 The biological fertilizer had a significant effect on the rate of . contentRoot from nitrogen, the concentration exceeded 1500 gr. -1 seedlings of bio-fertilizer were significant in giving the highest rate NS. contentRoot from nitrogen reached $1.6867 \%$ Compared to the lowest rate of content TheRoot from nitrogen reach $1.3283 \%$ When the comparison treatment is $0 \mathrm{~g}$. seedling -1 . The results presented in the same table indicate that the variety did not have a significant effect on the rate of . contentRoot from nitrogen The results of the same table show the presence of significant interactions, as the reason for the interference consists of $1500 \mathrm{~g}$. -1 seedlings of bio-fertilizer with cultivarblack Diyala highest rate NS. contentRoot from Nitrogen reached $1.6867 \%$ which did not differ significantly from the interference consisting of1500 gr. -1 seedlings of bio-fertilizer with cultivarmy minister Whereas, the interference formed was 0 g. -1 seedlings of bio-fertilizer with cultivarblack Diyala lowest rate NS. contentRoot from nitrogen reached $1.3100 \%$.

Table (4): the effect ofimpregnated bio ( seek ) and the variety and the interaction between them in the nitrogen content of the roots $\%$

\begin{tabular}{|c|c|c|c|c|c||}
\hline \multirow{2}{*}{$\begin{array}{c}\text { Varieties Effect } \\
\text { Rate }\end{array}$} & \multicolumn{4}{|c|}{ Biofertilizer concentration (gm. seedlings -1) } & \multirow{2}{*}{ Categories } \\
\cline { 2 - 6 } & 1500 & 1000 & 500 & 0 & black Diyala \\
\hline 1.5208 & 1.6867 & 1.6367 & 1.4500 & 1.3100 & Al-Waziri \\
\hline 1.5542 & 1.6867 & 1.6500 & 1.5333 & 1.3467 & $\begin{array}{c}\text { Biofertilizer } \\
\text { effect rate }\end{array}$ \\
\hline & 1.6867 & 1.6433 & 1.4917 & 1.3283 & $\begin{array}{c}\text { The slightest } \\
\text { difference } \\
\text { LSD (0.05) }\end{array}$ \\
\hline
\end{tabular}

\section{4- The phosphorous content of the roots $\%$}

The results presented in the table indicate 19 The biological fertilizer had a significant effect on the rate of . contentRoot from phosphorous, the concentration exceeded 1500 gr. -1 seedlings of bio-fertilizer were significant in giving the highest rate NS. contentRoot from phosphorous reached $0.5683 \%$ Compared to the lowest rate of content TheRoot from nitrogen reach $0.2533 \%$ When the comparison treatment is $0 \mathrm{~g}$. seedling -1 . The results presented in the same table indicate that NSto class Effect significant in rate . contentRoot from phosphorous Where the class outperformed my minister and scored the highest rate of $0.4533 \%$, while the black variety Diyala recorded the lowest rate of $0.4233 \%$. The results of the same table show the presence of significant interactions, as the reason for the interference consists of 1500 g. -1 seedlings of bio-fertilizer with cultivarmy minister highest rate NS. contentRoot from phosphorous reached $0.5800 \%$ Whereas, the interference formed was $0 \mathrm{~g}$. -1 seedlings of bio-fertilizer with cultivarblack Diyala lowest rate NS. contentRoot from phosphorous reached $0.2367 \%$. 
Table (5): the effect ofimpregnated bio ( seek ) and the variety and the interaction between them in the phosphorous content of the roots $\%$

\begin{tabular}{|c|c|c|c|c|c|}
\hline \multirow{2}{*}{$\begin{array}{c}\text { Varieties Effect } \\
\text { Rate }\end{array}$} & \multicolumn{4}{|c|}{ Biofertilizer concentration (gm. seedlings -1) } & \multirow{2}{*}{ Categories } \\
\cline { 2 - 6 } & 1500 & 1000 & 500 & 0 & black Diyala \\
\hline 0.4233 & 0.5567 & 0.5033 & 0.3967 & 0.2367 & Al-Waziri \\
\hline 0.4533 & 0.5800 & 0.5333 & 0.4300 & 0.2700 & Biofertilizer effect \\
& 0.5683 & 0.5183 & 0.4133 & 0.2533 & $\begin{array}{c}\text { rate } \\
\text { The slightest } \\
\text { difference } \\
\text { Liofertilizer }=0.02238 \text { class }=0.01583 \\
\text { overlap }=0.03166\end{array}$ \\
\hline
\end{tabular}

\section{5- Potassium content of roots $\%$}

The results presented in the table indicate 20 The biological fertilizer had a significant effect on the rate of Potassium content of roots The concentration exceeded 1500 g. -1 seedlings of bio-fertilizer were significant in giving the highest rate ofPotassium content of roots reached $1.4017 \%$ Compared to the lowest rate of The nitrogen content of the roots reach $0.8800 \%$ When the comparison treatment is $0 \mathrm{~g}$. seedling -1 . The results presented in the same table indicate that The variety had a significant effect on the rate of Potassium content of roots Where the class outperformed my minister and scored the highest rate of $1.2383 \%$, while the Aswad Diyala variety recorded the lowest rate of $1.1983 \%$. The results of the same table show the presence of significant interactions, as the reason for the interference consists of 1500 g. Seedlings -1 of bio-fertilizer with the variety Aswad Diyala, the highest rateThe content of potassium in roots reached $1.4033 \%$ Which did not differ significantly from the interference consisting of $1500 \mathrm{~g}$. Seedlings-1 of biofertilizer with Waziri cultivar, while the interaction formed was 0 gm. Seedlings -1 of bio-fertilizer with the lowest rate Aswad Diyala varietyPotassium content of roots Which did not differ significantly from the interference consisting of $0 \mathrm{~g}$. -1 seedlings of bio-fertilizer with the cultivar Waziri, which reached $0.8800 \%$.

Table (6): the effect ofimpregnated bio ( seek ) and the class and overlap between them in the content of the roots ofpotassium $\%$

\begin{tabular}{|c|c|c|c|c|c||}
\hline \multirow{2}{*}{$\begin{array}{c}\text { Varieties Effect } \\
\text { Rate }\end{array}$} & \multicolumn{4}{|c|}{. concentrationimpregnated Bio (gm. seedlings -1) } & \multirow{2}{*}{ Categories } \\
\cline { 2 - 5 } & 1500 & 1000 & 500 & 0 & \\
\hline \multirow{2}{*}{1.1983} & 1.4033 & 1.2867 & 1.2233 & 0.8800 & black Diyala \\
\hline
\end{tabular}




\begin{tabular}{|c|c|c|c|c|c||}
\hline 1.2383 & 1.4000 & 1.3700 & 1.3033 & 0.8800 & Al-Waziri \\
\hline & 1.4017 & 1.3283 & 1.2633 & 0.8800 & $\begin{array}{c}\text {. effect } \\
\text { rateimpregna } \\
\text { ted bio }\end{array}$ \\
\hline \multicolumn{3}{|c|}{ overlap = 0.06478 } \\
\multicolumn{3}{|c|}{ Theimpregnated bio = 0.04581class = 0.03239} & $\begin{array}{c}\text { The slightest } \\
\text { difference } \\
\text { LSD (0.05) }\end{array}$ \\
\hline
\end{tabular}

\section{DISCUSSION}

\section{1- Effect of a bio-fertilizer on the vegetative characteristics of fig seedlings.}

The reason for the increase in the content of nutrients in the leaves and roots is due to the role of the bio-fertilizer in releasing the major elements ready for absorption, which are ready for absorption by the roots and thus Its concentration in the plant increasesbutler ,2006) These results are in agreement with the findings (Vandenham, 1997 inhis study on fig trees. as Biofertilizers increase growth The root system of the plant, because Containing Some plant growth stimulants Which increases the readiness of nutrients Leading to me Increasing the efficiency of root absorption of nutrients in the soil (the local ,2005), These results are in agreement with the It was mentioned by (Al-Samarrai, 2009) in his study on citrus seedlings, as he mentioned that the bio-fertilizer increases the availability of nutrients in the soil and thus obtaining significant differences in the content of leaves from chlorophyll, carbohydrates and mineral elements. It also agrees with what he mentioned (TheFriend ,2015 ) In his study of olive trees, These results are also in agreement with the findings Mohjej and Elhayani (2015) In a study on apricot trees , as well as agree with ( El-sabbagh and others, 2011) In his study of grape vines . also agree with (El-Khayat and Abdel Rehiem, 2013) When studying it on orange trees .

\section{Effect of the variety on the vegetative characteristics of fig seedlings}

The superiority of the Waziri variety may be attributed to the Aswad Diyala variety in a The qualities ( The content of the roots of phosphorous is table 6 and the content of the roots of potassium is table 7 ) To the genetic nature of the two cultivars, where the cultivars differ in the nature of their growth, their external appearance and the nature of their response to environmental conditions depending on the difference in their genetic composition. These results are in agreement with the above ( Khalil et al ,2010 ) In his study on apricot seedlings And( Shalash et al , 2012 ) In his study on olive seedlings and (Al-Safi, 1997) In his study on fig seedlings and (Al-Zebari, 2011) In his study of figs, 


\section{References}

Al-Rawi Kisha, Mahmoud and Abdel Aziz Muhammad Khalaf Allah, 2000. Design and analysis of agricultural experiments. Ministry of Higher Education and Scientific Research, Dar Al-Kutub Institution for Printing and Publishing, University of Mosul - Iraq.

Al-Samarrai, Faleh Hassan Saeed, Hadi Mahdi Abboud, Muayad Rajab Abboud, Osama Abdullah Alwan and Ali Jabbar.(2009). The efficacy of isolates of mushroomsTrichodermaspp. In the stability of citrus seedlings after transferring and increasing the readiness of some nutrients to it. The Tenth Arab Conference on Plant Protection. Beirut 26-30 October. Lebanon .

Al-Siddiq, Abu Bakr Ahmed (2015). The effect of organic fertilizerMaster Humic Fluvic acid on olive trees. Master Thesis . University of Khartoum, Sudan.

Al-Saeedi, Mr. Hamid.( 2005 ). Breeding plants under different stress conditions and scarce resources (Low in put) and its physiological foundations. Universities Publishing House - Tanta University - Egypt.

Mohjaj, Muhammad Abdullah and Ali Muhammad Abd al-Hayani.( 2015). Effect of biofertilizers and the date of grafting on the success rate of buds and some growth characteristics of three apricot cultivars. Zagazig Journal of Agricultural Research.42 (6): 1348-1339.

Al-Safi, Saleh Abdel-Sattar Abdel-Wahhab. 1997 .Effect of stem cutting location and auxin on rooting of three fig cultivars. Al-Taqni Journal 1 (38) 69-74.

Al-Zibari, Suleiman Muhammad Kako (2011).auxin effect (IBA) Rooting and growth of seedlings of six varieties of figs. Journal of Tikrit University of Agricultural Sciences. 11(1): 119-125.

Attia, Khaled Mohsen (2020) . The effect of nano and bio-fertilizer on the growth and production of active substances of the golden stick plant Solidago canadensisStudying its biological activity. Master Thesis . Department of biology . College of Science . Al-Qadisiyah University

Al-Jumaili, Alaa Abdul-Razzaq Muhammad, and Jabbar Hassan Al-Dujaili.1989). Fruit Production, Ministry of Higher Education and Scientific Research, House of Books for Printing and Publishing, University of Mosul, Iraq.

Al-Allaf, Iyad Hani and Iyad Tariq, the flag carrier (2014) The relationship of cuttings type and concentrations of auxins in increasing the rooting ability of stem cuttings of two figs cultivars Mesopotamia Journal of Agriculture Volume (42) Issue (1).

Abd El-Samad, GA; MA Galal, MM El-Badry, and SM Ali , (2017).Response of fig trees to bio-fertilization and growth media. The 2nd Confirm Integrated Pest Management, 16-18 Jan. Faculty of Agric- El-Fayoum Univ., Egypt, pp. 2I-39.

Abdelaal, S. ; H. E. Mohamed, and SS Kabeil, (2010). Microbial bio-fertilization approaches to improve yield and quality of fig trees and reducing the survival of nematode in the soil. Journal of American Science, 6(12):264-272. 
Abd-Rabouo, FA (2016). Effect of microbien, phosphorien and effective micro-organisms (EM) as bio-stimulants on growth of fig trees . Egypt. J. Apple. Sci., 23(6):673-693.

Borie, F. , R. Rubio and A. Morales. (2008).Arbscular Mycorrhizal Fungi and Soil Aggregation. J. Soil Sci. Plant Nutr. $8(2): 9-18$.

Buragohain, S., B. Sarma, DJ Nath, N. Gogoi, RS Meena and R. Lal (2018)."Effect of 10 years of biofertiliser use on soil quality and rice yield on an Inceptisol in Assam, India." Soil Research 56(1): 49-58.

Butler, T.2006. Bio stimulating Sports turf . Pitchcare,1-3.

Dvornic, CE ; GS Howell and Elore, AJ .1965. Influence of cro load on photosynthesis and dry matter partition at seyval grap vines II. Seasonal change in single leaf and whole wine photosynthesis .Are J. Endvitic. 46(4):469-477.

Ferguson, L.; T.J. Michaelides and HH Shorey. (1999).The California Fig Industry. Univ. California. USA

Isaac, O., (2000) . Die Ringeblome a well-known medicinal herb under newst considerations. Hippocrates verlag Gmbh, Stuttgart. PP: 138-142.

Ismail, O. M, OF Dakhly and MN Ismail. (2011). Influence of some bacteria strains and algae as biofertilizers on growth of bitter orange seedlings. Australian Journal of Basic and Applied Sciences, 5(11): 1285-1289.

Khehra, S and JS, Bal. (2014).Influence of organic and inorganic nutrient sources on growth of lemon (Citrus limon L. Burm.) cv. Baramasi.Journal of Experimental Biology and Agricultural Sciences.2(1S):126-129.

Okur, N. (2018)."A Review-Bio-Fertilizers-Power of Beneficial Microorganisms in Soils." Biomedical Journal of Scientific \& Technical Research 4(4): 4028-4029.

Page, AL ; Miller, R. H. and Keeney, DR (1982).Method of soil and analysis Part 2, 2nd ed, Agron. 9. Publisher, Madison, Wisconsin, USA.

Vandanham. (1997).Effect of Em in crop production ( fig trees ) . Plant and Soil Journal, 255(2):571-586. 